\title{
Localization of sound following binaural intensity imbalance'
}

\section{LLOYd F. ELFNER AND DAVID R. PERROTT \\ KENT STATE UNIVERSITY}

An experiment is reported on the effect of a 63 min. exposure to an intermittent $700 \mathrm{~Hz}$ tone dichotically presented with a $50 \mathrm{~dB}$ interaural intensity imbalance, on the localization function for a $1,000 \mathrm{~Hz}$ tone. While no absolute thre shold shifts were noted for the $1,000 \mathrm{~Hz}$ tone, significant changes were observed in the localization function.

Elfner \& Carlson (1965) reported that prolonged exposure of one ear to the amplification of auditory input by means of a hearing aid produced decrements in Ss' ability to lateralize a binaurally produced auditory image. This decrement was demonstrated by an increase in the interaural intensity imbalance required to shift the sound image to the unexposed ear. Preliminary results from a study in our laboratory indicate that similar changes in the lateralization function can be observed in the absence of change in absolute threshold. The present study used the latter technique in an attempt to assess the effects of prolonged exposure to an interaural intensity imbalance on the ability to localize a sound source in space.

Method

Ten Ss from an introductory course in psychology at Kent State University were employed. All exhibited hearing within the normal range.

A $1000 \mathrm{~Hz}$ signal was led from its audio-oscillator (Hewlett-Packard, Model 204B) through a decade attenuator (Hewlett-Packard, Model 350) to a loudspeaker having an $8 \mathrm{~mm}$ opening. The loudspeaker was mounted on a sound-boom permitting movement over an arc of 20 degrees to either side of the S's midline, on an $8 \mathrm{ft}$ radius. An electronic timer (Hunter, Model 100-C) was used to program the signal.

$S$ was seated in a sound-treated room facing the loudspeaker. Absolute thresholds were determined for a $1000 \mathrm{~Hz}$ tone. $\mathrm{S}$ was then blindfolded and tested for his ability to localize the sound source. Localization tests were then run as follows: The loudspeaker was moved to one of three locations, 20 degrees to the right, 20 degrees to the left, or directly ahead of the S. A $1000 \mathrm{~Hz}$ tone was presented at $40 \mathrm{~dB}$ sensation level (SL). Five 1000-msec pulses of tone were presented with a $2500 \mathrm{msec}$ interpulse interval, for a total test trial of $15 \mathrm{sec}$. During the test trial S's task was to point his finger at the apparent source of the sound. The finger was fastened to a pointer device which could be moved in an arc of 120 degrees. The position of the pointer was recorded following the fifth pulse on each trial. Three trials were run at each position for a total of nine trials. The location of the speaker was varied from trial to trial in a random manner.

The exposure condition was then run in the following manner: In an audiometric test room (IAC, Model 1201A), absolute thresholds for a $700 \mathrm{~Hz}$ tone, for each ear of $S$, were determined using the method of limits. $S$ was then exposed to a $700 \mathrm{~Hz}$ tone at $70 \mathrm{~dB}$ $\mathrm{SL}$ in the right and $20 \mathrm{~dB}$ in the left ear. This mismatched input was presented intermittently with a $4 \mathrm{sec}$ on time and a 1 sec off time. This cycle was repeated continuously for $63 \mathrm{~min}$. All stimulus presentations were made via earphones (Koss, Model SP-3). Following this exposure period the absolute threshold for the $700 \mathrm{~Hz}$ tone was determined at the right ear. $S$ was then returned to the sound-treated room and retested on the localization task with the $1000 \mathrm{~Hz}$ test signal. The average time between the end of the exposure period and the end of the final localization trial was $8 \mathrm{~min}$.

\section{Resulis}

Extended exposure to the binaural intensity mismatch had no apparent effect on the listener's auditory sensitivity. Absolute thresholds at the right ear, the more strongly stimulated ear, demonstrated no change in the absolute threshold for the $1000 \mathrm{~Hz}$ test signal.

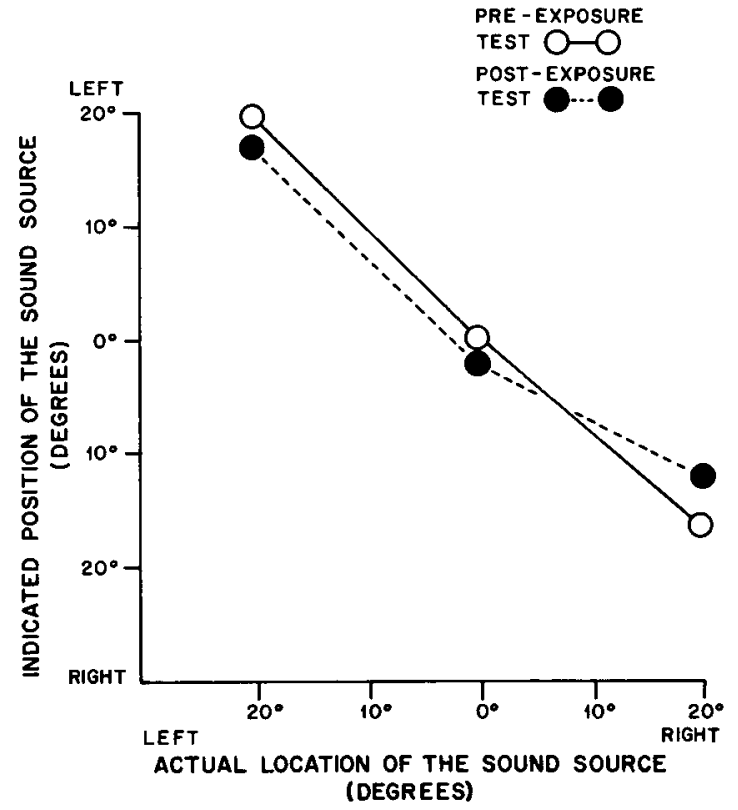

Fig. 1. Mean indicated position of a sound source as a function of the actual location of the sound source (degrees) for the pre- and post-exposure conditions. 
The solid lines in Fig. 1 show the mean indicated position of the sound source for the pre-exposure trials. The broken lines in Fig. 1 show the mean indicated position of the sound source following exposure to the intensity mismatch. The only significant increase in variability of responding occurred for the medial localization task $(F=3.69, d f=9 / 9, p<.05)$. If anything, there was a slight decrease in variability in localization response following exposure at the lateral positions. In terms of direction of shift of the indicated position between pre- and post-exposure, the following occurred: (1) For the $20^{\circ}$ left condition, eight of the $10 \mathrm{Ss}$ indicated the source had shifted to the right; (2) For the $20^{\circ}$ right condition, all $10 \mathrm{Ss}$ indicated the source had shifted to the left; (3) For the medial condition, seven of the 10 showed slight shifts to the right. In terms of the mean amount of shift of the image between pre- and post-exposure, the following results were obtained: (1) For the $20^{\circ}$ left condition, $2.6^{\circ}$ to the right; (2) For the $20^{\circ}$ right condition, $5^{\circ}$ to the left; (3) for the medial position, $1.9^{\circ}$ to the right. The results of an analysis of variance performed on the experimental findings indicate that the location of the speaker was found to be a significant source of variation $(F=10.1, d f=2 / 18, p<.01$ ) Similarly, the interaction between Exposure and Location was significant $(F=8.5, \mathrm{df}=2 / 18, \mathrm{p}<.01)$. A direct-difference $t$ test indicated that for the $20^{\circ}$ left condition, the shift of the source was significant $(t=2.36$, df $=9, p<.05)$. Likewise, for the $20^{\circ}$ right condition, the shift of the apparent source was significant $(t=4.5, d f=9, p<.01)$. No reliable shift was noted for the medial condition.

It is apparent from the experimental results that exposure of the auditory system to a binaural intensity mismatch affects the ability to localize the source of a sound. Although no significant change in the mean indicated position was found for the medial location, the significant increase in variability of responding is Indicative of a decrement in the localization function.

The significant shifts in the apparent source of the auditory image in the lateral positions were in both cases toward the medial location. Also, no significant increase in the variability of the responses was noted following the exposure period. These findings are indicative of a systematic change in the localization function.

The shifts of the image found in the lateral positions are analogous to the findings of the Elfner \& Carlson (1965) study. The increase in the critical interaural intensity difference observed in the lateralization task is compatible with the shift of the images from lateral to more medial locations following exposure to the intensity imbalance. A possible explanation for this effect is that the exposure to a prolonged intensity imbalance reduces the listener's sensitivity to interaural intensity differences. This suggestion parallels the observation by von Bekesy (1960) that exposure to a single tone can reduce the listener's sensitivity to intensity differences across a wide range of frequencies.

\section{References}

von Bekesy, G. Experiments in hearing. Translated and edited by E. G. Wever. New York: McGraw-Hill Book Company, Inc., 1960. Pp. 354-358.

Elfner, L. F., \& Carlson, Carol. Lateralization of pure tones as a function of prolonged binaural intensity mismatch. Psychon. Sci.. $1965,2,27-28$.

\section{Hote}

1. This study was supported by National Institutes of Health Research Grant No. MH 11181. 